\title{
Simulating a Compressed Air Energy Storage System for a Net Zero Energy Building in Tropics
}

\author{
J. Castaing-Lasvignottes*, M. David, S. Simpore, O. Marc, F. Garde \\ Laboratoire de Physique Et Ingénierie Mathématique pour l'Energie et l'environnemeNT (PIMENT), University of \\ Reunion Island, 40 Av.de SOWETO, 97410, Saint Pierre, France. \\ E-mail: ${ }^{*}$ jean.castaing-lasvignottes@univ-reunion.fr
}

Received 21 November 2015, Revised 09 May 2016, Accepted 04 July 2016

\begin{abstract}
Meeting the demand in electricity for houses or buildings provided by means of photovoltaic panels is relatively tricky, especially because of the stochastic character of solar radiation. There are some solutions in terms of storage and among them, the one consisting in converting electricity in high-pressure compressed air, seems promising. This option is under investigation in a building of teaching classes at Reunion University (a French island situated in the Indian Ocean, at the east of Madagascar). The aim in terms of consumption is $25 \mathrm{kWh}_{\mathrm{fe}} \cdot \mathrm{m}_{\mathrm{NFA}}^{-2} \cdot \mathrm{year}^{-1}$ leading, if possible to a NetZEB (Zero Energy Building). Therefore, it has been envisaged to produce the electricity by means of PV panels, to consume the major part and to store the extra production for use at night and during periods of overcast sky. The solution that has been investigated, consists in compressing air in high-pressure storage tanks and to produce electricity later using a turbine. A dynamic numerical model has been built, taking a specific given load profile and local climatic data into consideration, in order to estimate the production. The whole system depends mainly on the PV panel area, the storage tank volume and the pressure range. The objective is to reduce the amount of energy provided by the external grid to the minimum, leading to the maximum autonomy of this system. First results have been obtained and are explained in terms of pressure and power evolution in the final section of this paper.
\end{abstract}

\section{Keywords: Compressed air energy storage; modelling; renewable energy; simulation; storage.}

\section{Introduction}

The electricity generation in tropical islands has to face the continuous growing demand of the building sector, which represents usually more than $80 \%$ of the electricity consumed. Electricity in tropical islands is unfortunately mainly generated by fossil fuels with no possibility to connect the grid to other bordering countries and so the carbon footprint is very high.

Some islands like La Réunion have launched a very ambitious energy program to achieve self-sufficiency in electricity by 2030 , thanks to renewables [1]. In this French overseas territory situated in the Indian Ocean, off the east coast of Madagascar (Latitude 21S, Longitude 55.5E), the ratio of electricity produced by renewables is more than 30 $\%[1]$.

Photovoltaic is the most widely renewable either for large-scale power plants or PV systems on building roofs. In parallel, in recent years, the concept of Net Zero Energy Buildings has been developed tremendously and a lot of work has already been published about these buildings [2]. The main drawback in using such a source is due to the stochastic character of the solar radiation that contributes to highly transient and almost unpredictable variations in the electricity production. As an example, La Réunion experienced its first electric blackout in January 2014. One of the most efficient ways to avoid this, is to store the electricity when available and to reuse it when a lack of sun radiation occurs. This has to be considered on a time scale (night/day intermittency, cloud coverage) as well as on a geographic scale (one place being cloudy while another is sunny) especially in a mountainous area such as La Reunion. There are numerous solutions for storing energy from electricity conversion (chemically, mechanically, potentially...) depending on the power level produced and consumed as well as on the amount of energy stored. On the building scale (residential for instance) the most widely used system consists in storing electricity in batteries. This solution suffers from being relatively heavy and nonenvironmentally friendly. An alternative consisting in converting electricity into high-pressure compressed air, seems promising [3] as the required technology is relatively mature, available and has a moderate environmental impact. Such storage systems have been tested since the 80 's but mainly for high power levels (approximately one hundred MW [4]) and there is a lack of small-scale Compressed Air Energy Storage (CAES) systems. This option is under investigation in parallel to reducing consumption in buildings. Consequently, it was envisaged to produce the electricity by means of PV panels, to consume the major share and to store the extra production in order to be used either at night or during less intensive sunny periods. The solution that has been investigated consists in compressing air in high-pressure storage tanks, to produce electricity later using a turbine. Nevertheless, the system remains connected to the external grid in case extra electricity is required by the building or if too much electricity is produced by the PV plant and is not stored instantaneously. A dynamic numerical model has been built, taking a 
specific given load profile and local climatic data in consideration in order to estimate the production. The energetic analysis of the whole system is calculated and integrated over a year in order to assess the overall performance of this CAES system. The main objective is to reduce the amount of energy provided by the grid.

\section{Presentation of the Net Zero Energy Building used for this study: ENERPOS \\ 2.1 Climate of La Reunion}

La Reunion is located in the sub-tropical area in the southern hemisphere $(200 \mathrm{~km}$ West of Mauritius in the Indian Ocean). The climate is tropical along the coastline and is mainly characterized by:

1. An important mean solar radiation $\left(5.6 \mathrm{kWh} / \mathrm{m}^{2}\right.$.day, $2,044 \mathrm{kWh} / \mathrm{m}^{2}$.year);

2. A hot and humid season (from December to March) and a dry season (from June to September);

3. A constant gap of $8^{\circ} \mathrm{C}$ between the daytime and night time temperatures;

4. High temperatures in summer with the mean maximum air temperatures generally above $30^{\circ} \mathrm{C}$. At the same time, the level of humidity is approximately $60 \%$.

The ENERPOS Building is located in the second biggest city of La Reunion, Saint-Pierre, in the South of the island at a latitude of $21^{\circ} \mathrm{S}$. The weather conditions of Saint-Pierre are listed in Table 1.

Table 1. Climate Conditions in Saint-Pierre.

\begin{tabular}{ccccccc}
\hline & \multicolumn{3}{c}{ Air Temp $\left({ }^{\circ} \mathrm{C}\right)$} & RH & $\begin{array}{c}\text { Mean air } \\
\text { speed }\end{array}$ & $\begin{array}{c}\text { Mean global solar } \\
\text { radiation }\end{array}$ \\
\hline \multirow{3}{*}{ Summer } & Mean & Min & Max & $(\%)$ & $(\mathrm{m} / \mathrm{s})$ & $\left(\mathrm{kWh} / \mathrm{m}^{2}\right.$. day $)$ \\
Winter & 25.6 & 17.8 & 32.5 & 73 & 2.4 & 6.1 \\
\hline
\end{tabular}

\subsection{General Information about ENERPOS}

ENERPOS is one of the three buildings listed by the International Energy Agency as very efficient Net ZEBs in tropical areas. Various papers have already been published to present the design of the building [5], [6] and the experimental feedback [7].
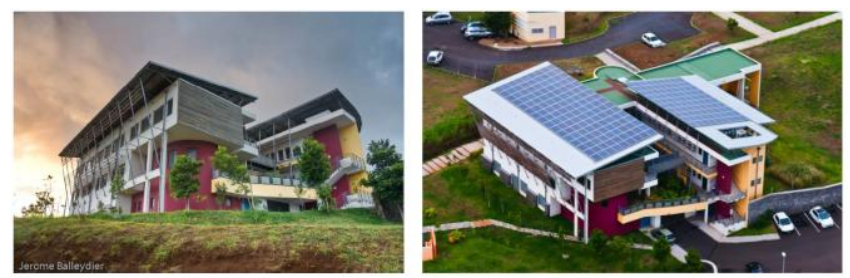

Figure 1. General view of ENERPOS (left) and aerial view (right) with the PV roofs. ENERPOS is composed of two parallel wings separated by a green patio. A car park is located underneath the patio and the left wing.

ENERPOS is a two-storey university building split into two parallels blocks separated by a green patio (Figure 1.). The blocks are composed of an administration zone on the ground level (7 offices and a meeting room), 2 computer rooms and 5 classrooms on ground and first floor for a total net floor area of $741 \mathrm{~m}^{2}$.

\subsection{Passive Design}

The building has been designed with the priority placed on passive solutions. The building is cross naturally ventilated. This is one of the two main principles that are mandatory in tropical climates to avoid air-conditioning. The second principle is to have a very efficient solar shading design. The porosity, i.e. the openings to facade surface ratio is $30 \%$ thanks to glass louvers which have the advantage of allowing the regulation of the airflow, while also providing protection against cyclones and break-ins. In the administration zone, the original feature of the project was to install indoor louvers which enhance the interior airflow. Another innovation was to install large ceiling fans in all spaces, including those with air-conditioning. The use of ceiling fans provides an additional air speed during the windless days and allows a transitional period before the use of active air-conditioning systems.

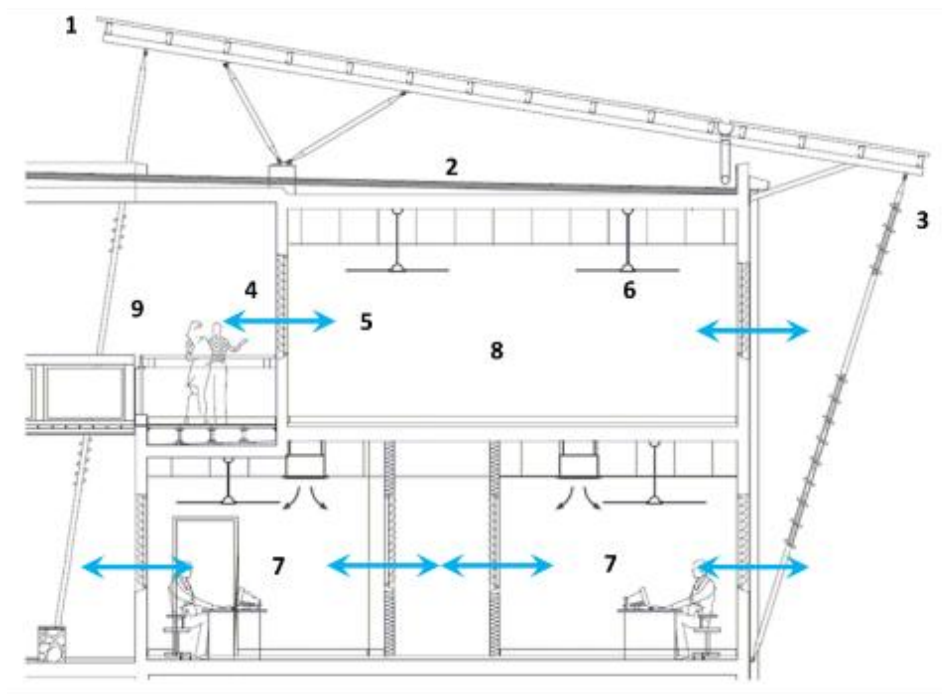

BIPV roof and sun protection

2 Insulated rood

3 Fixed solar shading - wooden strips

4 Louvered glass windows: WWR $=\mathbf{3 0} \%$

5 Cross natural ventilation

6 High performance ceiling fans $\left(1 / 10 \mathrm{~m}^{2}\right)$

7 Offices

8 Classroom

9 Exterior walkway

Figure 2. Passive principles of the ENERPOS building. 
Concerning the envelope, the roofing is insulated with a $10 \mathrm{~cm}$-layer of polystyrene and a ventilated BuildingIntegrated Photo Voltaic (BIPV) over-roof; the walls are made of concrete; the north and south facades have solar protections with shadings made of wooden strips; the east and west gables are insulated with mineral wood and a wooden siding (Figure 2.). The solar shadings have been designed thanks to 3D simulations and optimized to find a compromise between thermal efficiency and daylighting. Indeed, thanks to the cross natural ventilation, most of the spaces have a UDI (Useful Daylight Illuminance) of $90 \%$ at least. Even though two classrooms were not equipped with lighting appliances while simulations have demonstrated that during the working hours, the UDI was $100 \%$. All the design options have been assessed by in-situ experiments, occupant surveys and post occupancy evaluation [8].

\subsection{Energy Efficiency}

The energy performance of the active systems used is also very efficient and several actions of energy management procedures are conducted in order to decrease the total consumption. Concerning artificial lighting, the installed electric density is lower than in a standard building. It is about $6 \mathrm{~W} / \mathrm{m}^{2}$ for the classrooms. A 2-hour time delay insures that the lights are off at the end of the class. For the offices, the choice made was to use wall mounted lighting devices coupled with LED desk lamps that provides the required 300 Lux on the work plan. Thanks to that, the electric density in the offices is approximately $4.4 \mathrm{~W} / \mathrm{m}^{2}$.

Ceiling fans are used in the ENERPOS building to complement natural ventilation and to create an air speed on the skin of the occupants, thus increasing their comfort zone. A total of 55 ceiling fans with $132 \mathrm{~cm}$ blade diameter have been installed in all the offices and classrooms. The maximum power used for one ceiling fan is $70 \mathrm{~W}$, which represents $7 \mathrm{~W} / \mathrm{m}^{2}$ of density (assuming one ceiling fan for $10 \mathrm{~m}^{2}$ ). Compared to air-conditioning, the density is 10 times lower.

A variable refrigerant volume (VRV) air-conditioning system has been installed to cool the offices and the computer rooms during the warmer periods. But thanks to the natural ventilation and the use of ceiling fans, the cooling period has been significantly reduced to 6 weeks (only for the computing rooms) whereas in the other spaces (offices and tutorial rooms) air-conditioning is turned on exceptionally. In comparison to other standard buildings of the University, the air-conditioning period lasts usually 9 months.

A building management system controls and manages the air-conditioning (operating period, set point temperature); the schedules of exterior lighting and the follow-up of the consumptions by type of end-uses (lighting, ventilation, plug-loads, air-conditioning, lift...) to target the energy management procedures. The higher consumer end-use remains the plug loads accounting for approximately $50 \%$ of the total consumption of the building. To reduce this, the use of laptops and minicomputers (much less consumers than desktop computers) is encouraged in the offices.

\subsection{Renewable Energy}

The very low consumption of the building is balanced by $350 \mathrm{~m}^{2}$ of BIPV roofs. The PV panels are themselves situated on the roofs of both buildings, one half is north orientated while the other is south orientated (Figure 1.). The tilt angle of the PV cells is $9^{\circ}$ for both roofs. Besides electricity production, the PV panels provide a ventilated over-roof which creates a solar shading for the terrace-roof of the building and increases the protection from solar radiation.

\subsection{Energy Balance}

The underlying philosophy of ENERPOS is to balance the final energy consumption of all its uses with its PV production and to reduce the stretch of time within which the energy balance is reached. The advantage of tropical climate is indeed that there is simultaneity between the peak consumption (that corresponds to the use of ceiling fans or air-conditioning) and the maximum potential production (solar radiation for the PV panels).

Concerning the consumption, the building is fully monitored with energy meters by type of end-uses. The first results give an energy index of $14 \mathrm{kWh}_{\mathrm{fe}} \cdot \mathrm{m}_{\mathrm{NFA}}^{-2} \cdot \mathrm{y}^{-1}$; all uses are accounted for in the total. On the other end, the PV production is $98 \mathrm{kWh}_{\mathrm{fe}} \cdot \mathrm{m}_{\mathrm{NFA}}^{-2} \cdot \mathrm{y}^{-1}$, which is 7 times the consumption of the building.

\section{Principle and Modelling}

A large part of data recorded over the years and on a minute time basis on ENERPOS has been used as inputs in the model so as to take into account real electric load values (consumption) and real climatic conditions (for electric production). The model of CAES that is presented hereafter has the objective of taking into account the dynamic behavior of these conditions in order to size and simulate a system able to store and release energy when required. The first step that has been looked at, concerns the electric loads that are required for such a building and such uses. The produced electricity has then been modelled taking into consideration the measured efficiency of the PV panels, their implementation on the roof and local climatic conditions.

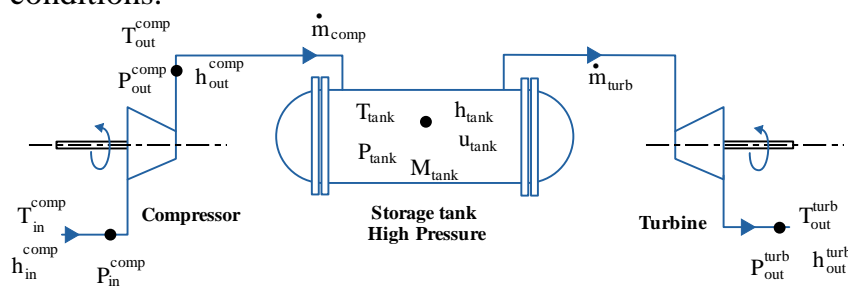

Figure 3. CAES flowsheet.

In order to match loads and production over time, a Compressed Air Energy Storage system has been considered. A typical CAES system is mainly composed of a compressor, a storage tank and a turbine as shown in Figure 3. As one of the objectives is to design such a system and to predict the behavior of the whole building, a dynamic model has been built to design the main components of the system.

$$
\begin{aligned}
& \frac{d M_{\text {stor }}}{d t}=\dot{m}_{\text {comp }}-\dot{m}_{t u r b} \\
& \frac{d U_{\text {stor }}}{d t}=\dot{m}_{\text {comp }} h_{\text {comp }}-\dot{m}_{t u r b} h_{t u r b}+\dot{Q}_{\text {stor/ext }}
\end{aligned}
$$

$\dot{W}_{\text {turb }}=\dot{m}_{\text {turb }}\left(h_{\text {turb }}^{\text {out }}-h_{\text {turb }}^{\text {in }}\right)$ 
$\dot{W}_{\text {comp }}=\dot{m}_{\text {comp }}\left(h_{\text {comp }}^{\text {out }}-h_{\text {comp }}^{\text {in }}\right)$

$\dot{m}_{\text {comp }}=\frac{\eta_{v} \text { Vol }}{v}$

$\eta_{\text {comp }}^{\text {is }}=\frac{h_{\text {comp }}^{\text {out, is }}-h_{\text {comp }}^{\text {in }}}{h_{\text {comp }}^{\text {out }}-h_{\text {comp }}^{\text {in, }}}$

$\eta_{\text {turb }}^{\text {is }}=\frac{h_{\text {turb }}^{\text {out }}-h_{\text {turb }}^{\text {in }}}{h_{\text {turb }}^{\text {out, is }}-h_{\text {turb }}^{\text {in, }}}$

An approach similar to the one introduced by Maton et al. [9] has been used and a set of equations has been written to take into account the mass and thermal inertia of the storage tank thanks to mass and energy balances, Eqs. (1), (2). In this equation, the term $\dot{Q}_{\text {stor/ext }}$ stands for external heat exchange between the storage tank and the environment $\dot{Q}_{\text {stor/ext }}=U A .\left(T_{\text {ext }}-T_{\text {stor }}\right)$ by means of an overall heat transfer coefficient $U A$ taking into account natural convection inside and outside the tank and conduction through the tank wall. Compressor and turbine energy fluxes ( $\dot{W}_{\text {comp }}$ and $\dot{W}_{\text {turb }}$ ) and mass flow rates ( $\dot{m}_{\text {comp }}$ and $\dot{m}_{\text {turb }}$ ) have been integrated, Eqs. (3), (4), considering their particular design over the definition and the use of isentropic and volumetric efficiencies, Eqs. (5)(7), these latter mainly depending on time-to-time working conditions (dynamic pressure ratio in particular). Work detailed in [10] and [11] has been used here, giving a pressure ratio dependency on the volumetric efficiency in the form $\eta_{v}=1-0.05 \cdot\left(\tau^{1 / 1.4}-1\right)$ and a constant value of 0.9 for $\eta_{\text {comp }}^{\text {is }}$ and $\eta_{\text {turb }}^{\text {is }}$. Considering the range of pressure and temperature investigated and as in many other works ([12], [13], [14]), an ideal gas law showed itself to be sufficiently accurate to depict pressure $(P)$, temperature $(T)$, specific enthalpy $(h)$, specific entropy $(s)$, specific internal energy $(u)$ and specific volume $(v)$ interactions.

Even in the exposed quite simple case, an important number of scenarios have to be considered to drive the whole system over time. At each time step, a first test is done in order to know whether the instantaneous production is higher than the consumption. If this is the case, the compressor can be turned on in order to store energy. As the compressor is a previously defined one (in terms of size as in performance), this extra production has to be compared to the one required by the compressor to start. If this is not the case, the missing power is taken from the electric grid to obtain the necessary required power level to drive the compressor. On the contrary, even if the compressor is turned on, if there is still an extra production of power, this latter is fed back into the grid. Each time the compressor is turned on, another test is done in order to check if a previously defined delay ( 3 min here) has been reached since the last compressor start-up so as to prevent this latter from short cycle behavior and bad working conditions.

At night or during cloudy periods, the consumption can be lower than the production and the turbine is then turned on in order to provide the difference. Contrary to the case of the compressor, the mass flow rate of air flowing through the turbine and leaving the storage tank (rags been considered here as controlled to match the exact required difference between electric loads and PV panel production, leading in this case to a non-dependency regarding the electric grid. Of course this can only be done if the amount of air and the storage pressure are sufficient to drive the turbine and meet these requirements. If not, this is an important point to mention as it reveals a down-sized tank and definitively stops the simulation in order to find a more accurate volume for the storage vessel. In addition to this technical selection criterion, another value in particular has been studied: the net energy flow, calculated by integriaing over time the electrical power entering or leaving the grid. One of the objectives of the system and of the design is to reduce the dependency on the electrical grid as much as possible. Considering the numerical and computational time aspects, the differential equations (1) have been solved by means of an Euler explicit method which was considered sufficient, allowing quite a rapid simulation time, as only about $3 \mathrm{~min}$ are required to simulate a whole year.

\section{Simulation and Results}

The electric consumption, PV production and exterior weather of the considered building have been recorded for several years on ENERPOS building. In order to simulate the behavior of the storage system, a data set of one year with a minute time step was built from these measurements. With such a time step, the temporal variations of the electric power from both consumption and production can be assessed accurately. The year 2012 was selected because it experienced a small amount of gaps in the minute data of the measured power consumption. The gaps in the power consumption of the selected year were filled in with the data from 2011. So, the missing data were replaced with the data of the same date and time of the previous year. The output of the building integrated PV plant was recorded with a daily time step and only the daily amount of energy was available. Using the weather data collected on the site, a statistical analysis permitted us to accurately assess to the efficiency of the PV system (10.87\% in this case). We used then this efficiency with the recorded minute solar irradiance of year 2012 to evaluate the output power of the PV plant. The data of solar radiation for this year did not present any gaps and so filing methods were not deemed necessary in this case. To study the advantage of storing energy instead of selling electricity over time, the simulated PV field area has been considerably reduced (only $100 \mathrm{~m}^{2}$ compared to the $370 \mathrm{~m}^{2}$ really installed) to match the total storage objective. The other main parameters used to simulate the building under these varying conditions are summarized in the Table 2.

Table 2. Simulation parameters.

\begin{tabular}{cccc}
\hline $\begin{array}{c}\text { Compressor swept } \\
\text { volume flow }\end{array}$ & $100 \mathrm{~m}^{3} \cdot \mathrm{h}^{-1}$ & $\begin{array}{c}\text { Turbine isentropic } \\
\text { efficiency }\end{array}$ & 0.9 \\
Tank volume & $5 \mathrm{~m}^{3}$ & $\begin{array}{c}\text { Compressor } \\
\text { isentropic efficiency }\end{array}$ & 0.9 \\
PV area & $100 \mathrm{~m}^{2}$ & & \\
\hline
\end{tabular}

The results presented hereafter are for the first two weeks in order to see what is happening in detail over a few days. Figure $4 \mathrm{a}$ is relative to the power produced by the PV panel field and to the power consumed by the building. It can be seen in the graph that there is no consumption during the first week in order to store an initial amount of energy in the tank. Comparing both evolutions, the difference 
between night and day is clearly marked in terms of production as well as in consumption. The difference between the weekends (lower but not null) and the rest of the week can also be seen regarding the evolution of the consumption. Figure $4 \mathrm{~b}$ plots the power supplied (input $=$ positive values) or given to the electric grid (output $=$ negative values). In terms of power, it is obvious to say that as PV production is available only a few hours a day, the energy balance requires a higher level of production compared to the continuous consumption whose power level is much lower in that case. If the storage had been ideal (no losses, ideal storage and release behavior) both areas under each curve should have given exactly the same value but in our case a higher amount of energy is required so as to store the extra amount of energy produced into the storage tank by means of the compressor. Figure $4 \mathrm{c}$ gives the pressure evolution inside the tank over the days. The average pressure after a few days of normal behavior is situated at about 70-80 bar.
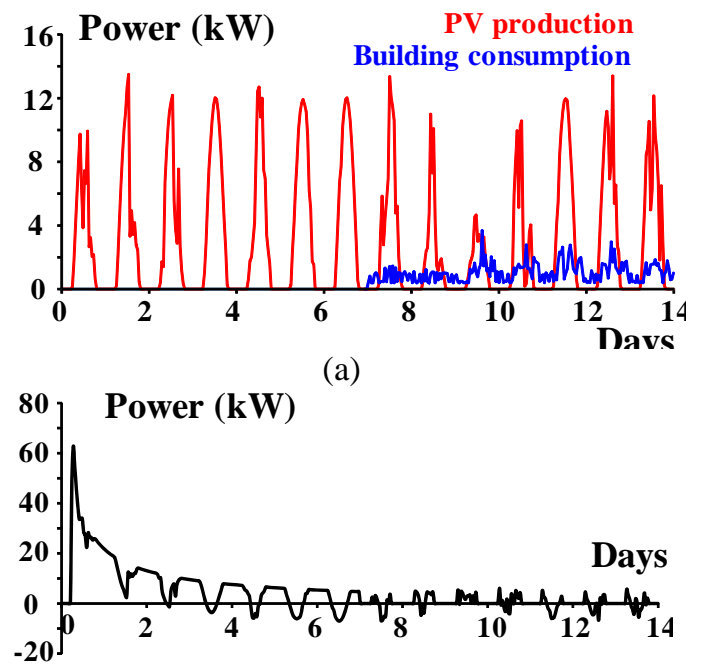

(b)

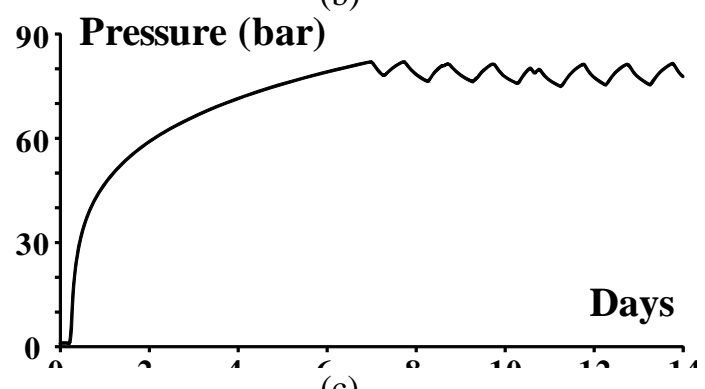

(c)

Figure 4. (a) Power produced and consumed by the system; (b) power exchanged with the grid; (c) pressure evolution in the storage tank for the first 2 week.

The simulation has been extended to a whole year in order to test the system, and to obtain overall information on a year basis.

Figure 5a represents firstly the power produced by the PV field over the studied year (2012). The observed variation is due to the seasonal changes between winter (May-August) and summer (November-February) and therefore to the corresponding modifications in the solar irradiance and day duration. The variations in these climatic conditions are much less sensitive on the consumption profile which is closely related to the rooms and office use (holydays from 15 July to 15 August for the lower values of consumption) and the air conditioning period mainly occurring in December for the highest recorded levels.
Figure $5 \mathrm{~b}$ is relative to the power level exchanged between the system and the electric grid. The positive values are relative to electric consumption and due to the use of the compressor as well as to the chosen strategy. As already explained before, sometimes, the power required by the compressor to run is higher than the remaining difference between the instantaneous production and consumption. Therefore, one can choose to release this extra power into the grid or, on the contrary, to supply the missing difference to turn on the compressor. Every time this has been the case, the chosen strategy has been to favor the storage of energy and therefore to increase the amount of energy supplied from the network. In the inverse situation (i.e. when there is still an over production once electricity has been consumed and stored), the remaining amount of electricity is released into the network and corresponds to the negative values of the figure $5 \mathrm{~b}$. Overall, the system releases more electricity into the network than it consumes from it.

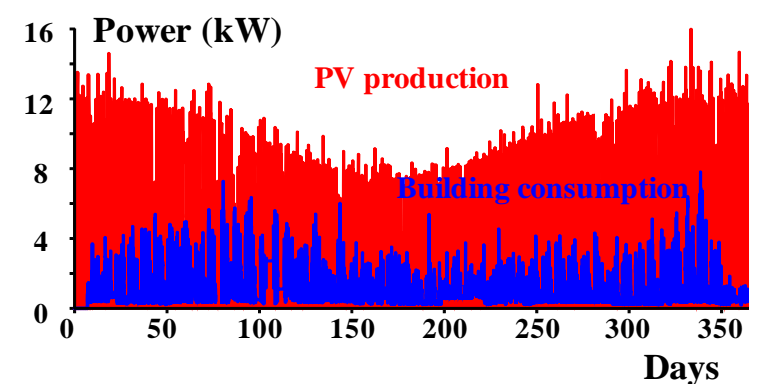

(a)

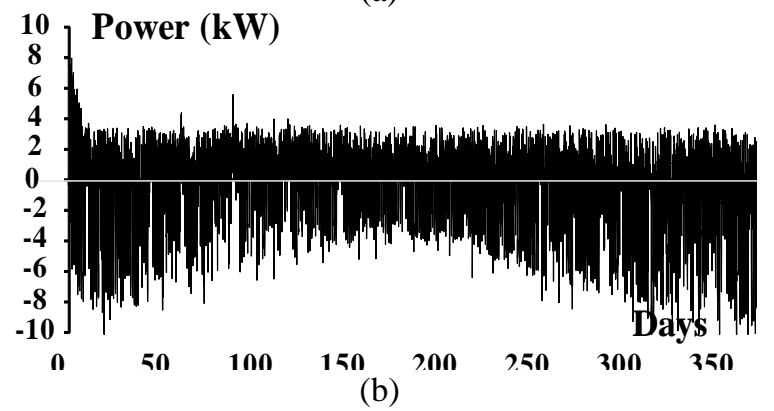

Figure 5. (a) Power produced and consumed by the system; (b) power exchanged with the grid over a whole year.

\section{Conclusions}

The objective of this paper was to present the construction of a dynamic model of a Compressed Air Energy Storage system connected to a PV plant and partly connected to the grid. The main goal was to take into account the transient nature of solar irradiance as well as the electric consumption profile of an existing building submitted to real operating conditions. This has been made possible thanks to the ENERPOS building and results about a whole year have been obtained. Simulation step time is 30 $s$ here so has to integrate the important variation of inputs in the model. It has to be noted that a particular effort has been made concerning the verification of the transient energy balances at every step time. Thus 3 tests where considered here: the first one on the storage tank itself, the second one on the system composed of the storage tank, the compressor and the turbine and the last one on the whole system (PV panels, grid connection, storage tank and consumption profile) in each case the errors were less than $3.10^{-6} \mathrm{~J}$ for 
each step time and led us to believe that the model was quite reliable.

From an overall energetic point of view, the energy provided by the PV plant is 79.2 GJ (22 MWh) for the whole year. In the meanwhile, the ENERPOS building has consumed 35.2 GJ (9.79 MWh). The difference between both has partly crossed the CAES so as to complete the energy balance when it deemed necessary (at night or on cloudy circumstances) and has partly been directly supplied to the grid. The latter represents in the studied case an amount of 9.13 GJ (2.54 MWh). The last important contribution to the energy balance corresponds to the one remaining stored in the tank after a year as well as few thermal losses between the storage tank and surroundings. Recent work from Jannelli et al. [15] has shown practically the same behavior on a radio based station equipped with a CAES and a PV power system and concludes also on the fact that the PV power unit is oversized. This paper also deals with a sizing-design methodology that we aim to adapt to our configuration soon. Our objective is then to optimize the system varying parameters such as the PV plant area, the storage tank volume, the compressor and turbine configuration and size (in terms of volume flow rate, type of compression [16], [17] and SSE: storage system efficiency) so as to reduce the electric dependency to the grid, and increase the overall efficiency as well as the annual energy supply factor (ESF: demand over production) that is equal to $44 \%$ in the studied case.

\begin{tabular}{ll}
\multicolumn{2}{c}{ Nomenclature } \\
$\mathrm{T}$ & temperature, $\mathrm{K}$ \\
$\mathrm{P}$ & pressure, $\mathrm{Pa}$ \\
$\mathrm{h}$ & specific enthalpy, $\mathrm{J} / \mathrm{kg} . \mathrm{K}$ \\
$\mathrm{U}$ & total internal energy, J \\
$\mathrm{t}$ & time, $\mathrm{s}$ \\
$\dot{\mathrm{W}}$ & mechanical power, $\mathrm{W}$ \\
$\dot{\mathrm{Q}}$ & heat flux, W \\
$\dot{\mathrm{m}}$ & mass flow rate, $\mathrm{kg} / \mathrm{s}$ \\
$v$ & specific volume, $\mathrm{m}^{3} / \mathrm{kg}$ \\
$\eta$ & efficiency \\
$\mathrm{M}$ & mass, $\mathrm{kg}$ \\
$\mathrm{Subscript}$ and superscript \\
comp & compressor \\
turb & turbine \\
is & isentropic \\
$\mathrm{v}$ & volumetric \\
in & input \\
out & output \\
stor & storage
\end{tabular}

\section{References:}

[1] J. P. Praene, M. David, F. Sinama, D. Morau, and O. Marc, "Renewable energy: Progressing towards a net zero energy island, the case of Reunion Island," Renew. Sustain. Energy Rev., 16, 426-442, 2012.

[2] IEA Task40/A52 [Online]. Available: http://task40.ieashc.org/ (accessed 2013).

[3] H. Lund and G. Salgi, "The role of compressed air energy storage (CAES) in future sustainable energy systems," Energy Convers. Manag., 50, 1172-1179, 2009.

[4] M. Raju and S. Kumar Khaitan, "Modeling and simulation of compressed air storage in caverns: a case study of the Huntorf plant," Appl. Energy, 89, 474-481, 2012.

[5] F. Garde, J. P. Praene, A. Bastide, F. Lucas, "Towards net zero energy buildings in hot climates: Part I, new tools and methods," ASHRAE Trans., vol. LV-11-C055, 2011.

[6] A. Lenoir, F. Garde, "Tropical NZEB," High Perform. Build. J., Summer, 43-55, 2012.

[7] A. Lenoir, F. Thellier, and F. Garde, "Towards Net Zero Energy Buildings in Hot Climate, Part 2: Experimental Feedback," ASHRAE Trans., 117, 2011.

[8] A. Lenoir, G. Baird, and F. Garde, "Post-occupancy evaluation and experimental feedback of a net zeroenergy building in a tropical climate," Archit. Sci. Rev., 55(3), 156-168, 2012.

[9] J.-P. Maton, L. Zhao, and J. Brouwer, "Dynamic modeling of compressed gas energy storage to complement renewable wind power intermittency," Int. J. Hydrog. Energy, 138, 7867-7880, 2013.

[10] C. O. R. Negrão, R. H. Erthal, D. E. V. Andrade, and L. W. da Silva, "A semi-empirical model for the unsteady-state simulation of reciprocating compressors for household refrigeration applications," Applied Thermal Eng., 31, 1114-1124, 2011.

[11] J. Castaing-Lasvignottes and S. Gibout, "Dynamic simulation of reciprocating refrigeration compressors and experimental validation," Int. J. Refrigeration, 33, 381-389, 2010.

[12] N. Hartmann, O. Vöhringer, C. Kruck, and L. Eltrop, "Simulation and analysis of different adiabatic compressed air energy storage plant configurations," Appl. Energy, 93, 541-548, 2012.

[13] Y. Zhang, K. Yang, X. Li, and J. Xu, "The thermodynamic effect of air storage chamber model on Advanced Adiabatic Compressed Air Energy Storage System," Renew. Energy, 57, 469-478, 2013.

[14] F. Baqari and B. Vahidi, "Small-compressed air energy storage system integrated with induction generator for metropolises: A case study," Renew. Sustain. Energy Rev., 21, 365-370, 2013.

[15] E. Jannelli, M. Minutillo, A. L. Lavadera, and G. Falcucci, "A small-scale CAES (compressed air energy storage) system for stand-alone renewable energy power plant for a radio base station: A sizingdesign methodology," Energy, 78, 313-322, 2014.

[16] Y. Zhang, K. Yang, X. Li, and J. Xu, "Thermodynamic analysis of energy conversion and transfer in hybrid system consisting of wind turbine and advanced adiabatic compressed air energy storage," Energy, 77, 460-477, 2014.

[17] N. M. Jubeh and Y. S. Najjar, "Green solution for power generation by adoption of adiabatic CAES system," Appl. Therm. Eng., 44, 85-89, 2012. 